\title{
Erratum to: Prospective Associations Between Peer Victimization and Dispositional Mindfulness in Early Adolescence
}

\author{
Nathaniel R. Riggs ${ }^{1}$ • Samantha M. Brown ${ }^{2}$
}

Published online: 28 February 2017

(C) Society for Prevention Research 2017

Erratum to: Prev Sci (2017)

DOI 10.1007/s11121-017-0750-z

The original version of this article unfortunately contained mistakes. Authors' affiliations are incorrect. Also, figure 1 image is incorrect. The text in the right side of the "Allocation" box should be changed to "Allocated to comparison group $(n=56) "$ with no other texts in the box.

The original article was corrected.

The online version of the original article can be found at http://dx.doi.org/ 10.1007/s11121-017-0750-z.

Nathaniel R. Riggs

nathaniel.riggs@colostate.edu

1 Human Development and Family Studies, Colorado State University, Fort Collins, CO, USA

2 Stress, Early Experiences, and Development Research Center, University of Denver, Denver, CO, USA 